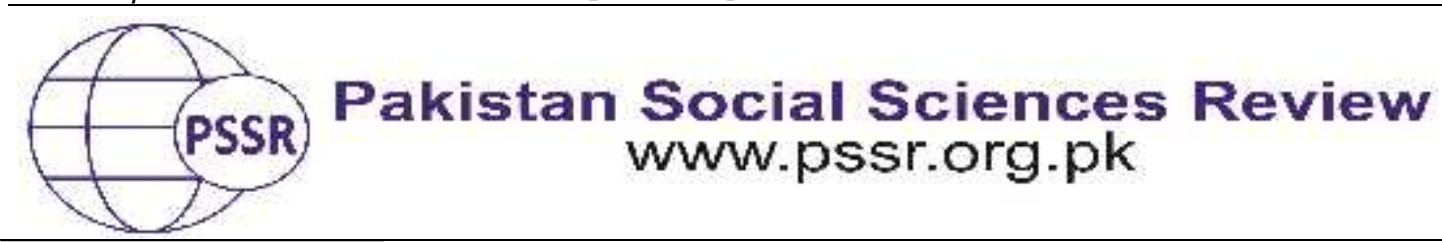

RESEARCH PAPER

\title{
Ethical Development of Young University Players through Involvement in Sports
}

\author{
Dr. Saeed Javed ${ }^{1}$ Dr. Abida Naseer ${ }^{2}$ Faryal Gul ${ }^{3}$
}

1. Assistant Professor, Department of Physical Education \& Sports Sciences, The Islamia University of Bahawalpur, Punjab, Pakistan

2. Assistant Professor, Department of Physical Education \& Sports Sciences, Government College University Faisalabad, Punjab, Pakistan

3. Lecturer, Department of Sports Sciences, University of Sargodha, Punjab, Pakistan

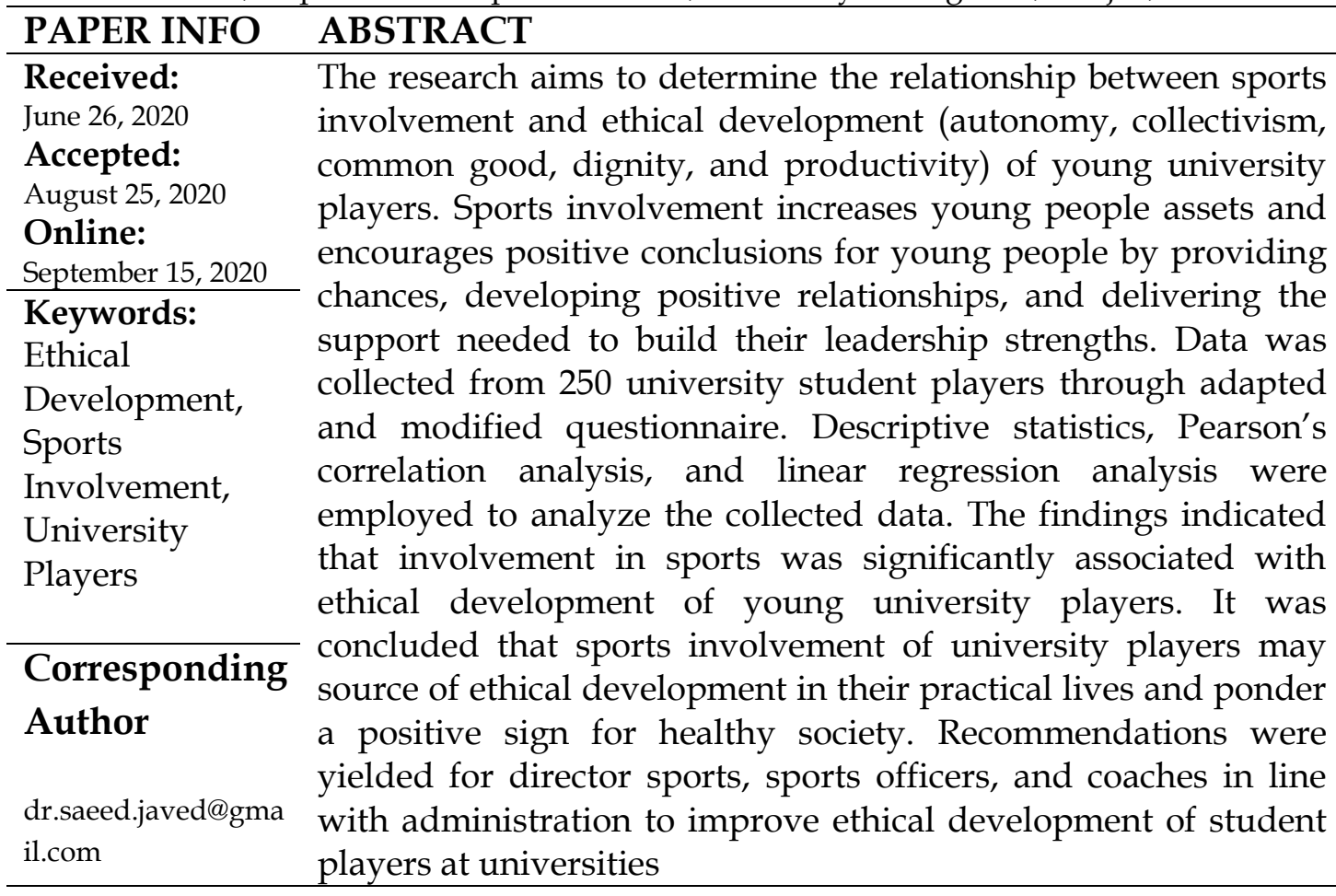

\section{Introduction}

Youth development is pro-social method that involves youth within their societies, administrations, peer clusters, and families in a way that is creative and positive distinguishes uses. According to Coakley (2011), youth development is a procedure that makes youngsters to meet the challenges of youth and development and achieve their maximum capacity. Youth development is helped through exercises that help them to create social, moral, enthusiastic, physical, and mental capacities. 
Sports considered as an action including physical effort and ability in which a person or a group contends with another or others for stimulation and the most wellknown sorted out actions in which engage (Tremblay et al., 2011). Similarly, physical activity can improve cardiovascular fitness, muscular strength and endurance, flexibility, and bone structure, ensuring optimal development in youth. According to Balsano, Phelps, Theokas, Lerner, \& Lerner (2009),wounds, burnout, traded off aptitude obtaining, and undiscovered ability/capability of youth competitors are on the ascent.

Sports can have an optimistic effect on the psychological wellbeing of youth and can build confidence and reduction pressure and anxiety (Fredericks \& Simpkins, 2012). It is well recognized that sport affects how youths develop socially. Through sports' individuals can involve in equivalence, independence and empowerment. Youth sports can teach vital life skills (Maslow \& Chung, 2013).Regarding mental development, there has long been a tradition that a healthy body leads to a healthy mind and that sports can support academic development in youth as well.

The relation between youth and sport is a solid one and historically youth have been fortified to play sports for a countless of benefits. The benefits of involvement in sports may be physical, existence, affective, communal, and mental. Regarding development, physical inactivity has been recognized as a risk of issues for a quantity of lifestyle illnesses and contributing in sports benefits overall health (Zeldin, Christens, \& Powers, 2013).

Sports cause young people to turn out to be better supporters of society. Today's youth needs to create abilities for achievement throughout everyday life. Through their pre-adult and young ages, the childhood is encountering issues in practices, relationships, precariousness and thoughts deficiency (Catalano, Berglund, Ryan, Lonczack, \& Hawkins, 2004). The current research was designed to investigate the development of youth through involvement in sports.

Sports activities are useful for appearing various noteworthy aptitudes. Adults face rivalry when they are applying for and keeping livelihoods, while youth face contention in scholastics and sports. Taking part in aggressive group activities at this youthful age offers a chance to comprehend the solid parts of rivalry in a neighbor domain. Understudies of any age who take an interest in games have been found to adapt better to rivalry in different aspects of their life (Lubans, Plotnikoff, \&Lubans, 2012).

Sports activities additionally help to physical prosperity. Moreover, physically unique youth will undoubtedly be sustenance mindful in their sustenance choices that are not adequately drawn in with a game (Gavin, Catalano, DavidFerdon, Gloppen, \& Markham, 2010). One of the fundamental reasons of school games are huge because it gives the movement, they may not regularly get. Clearly, this kind of development generally occurs after school. Most noticeably, these sorts 
of activities consolidate genuine amusements, for instance, football, basketball, baseball, tennis, Olympic style sports and soccer yet likewise may join entertainment focus beguilements and various preoccupations (Durlak, Weissberg, Dymnicki, \&Schellinger, 2011).

Youth participated in sports well before sorted out classes existed. Most recreations were played casually in parks or in the city. Numerous grown-ups recall those occasions when they played and went after fun. While, youth were having a fabulous time, they additionally profited by games in two noteworthy ways, physically and mentally. Nearby businesses, guardians accept that partaking in youth sports is imperative to a kid's advancement.

A mentor expressed that it is ideal for children to make a commitment, work their hardest, and get the prizes of positive certainty, accomplishments, sportsmanship, request, and time the officials too (Kegler, Young, Marshall, Bui, \&Rodine, 2005).According to Choi, Harachi, Gillmore, and Catalano(2005), youth associated with games/exercises revealed a more elevated amount of psychosocial development. Moreover, youth sports inclusion improves the procurement of physical advantages by members, just as different social and mental advantages. In this way, an investigation looking at support in youth sports and its impact on the improvement of enthusiastic knowledge shows up justified.

Sports can contribute fundamentally to global, national, and neighborhood endeavors to give youth a solid begin. Sports can help the individuals who have not got a decent begin, and outfit youth with abilities, individual, and social assets, and bolster expected to make key life changes effectively.

Youth enter in sports for many different reasons and out of a variety of motives, from wanting to join in on an activity their friends are getting involved into parents signing them up in hopes of them enjoying sport as they once had. Fun, ability improvement, association, wellness, challenge, and achievement/status to be the most consistently appearing youth motives for sports participation (Jones \& Perkins, 2006). Athletes find the enjoyment motive in sports through mastery climate, positive interactions amongst teammates, receiving support from teammates and coaches, and coach acknowledgement of satisfaction with the player's performance (Fredericks \& Simpkins, 2012). Motives for participation also appear to be shifting due to the increasing trend of starting athletes at as early of an age as possible so they have more time to specialize in their sports of choice in hopes of increasing their likelihood of being successful and competitive(Zeldin et al., 2013).

In the context of sports, coaches, parents, and peers typically come to mind. In this regard, the coach is the main contributing agent within sports. The coach is typically seen as an individual who possesses the skills that will need to be learned; naturally putting them in a role as a mentor to those they coach (Catalano et al., 2004). Instructors, at any capacity, have a great influence over how the learning environment is shaped and a child's experience within that learning environment 
(Lubans et al., 2012).Coaches, parents, and peers not only have a significant impact on youths' development, but also on their participation in sports. Each social agent has a unique influence on the environment and climate of sport, which has a direct relationship with youth development.

Although the sports domain is one that is predominately created by the coaches and athletes, other factors contribute to what the environment and climate is like as well. However, environment and climate progressively should be done to incorporate family, school, and the more extensive network into structure equipped competitors and even more critically, positive and sound natives (Gavin et al., 2010).Athletes who described their team climate as performance-oriented (egoinvolving) described their environment as one where teammates were constantly competing against one another to be the best, mistakes made by athletes were punished, and favoritism was shown to certain athletes (Durlak et al., 2011). The youth sport environment is thought to be this microcosm for development and learning to occur. In comparison, more professional oriented sport environments are primarily focused on production (winning), commercialization, and entertainment (Kegler et al., 2005). research:

The followings hypotheses of the research were developed for the present

H1 There is significant relationship between sports involvement and ethical development of young players at universities.

$\mathrm{H} 2$ There is significant influence of sports involvement on ethical development of young university players.

\section{Material and Methods}

Population can be explaining as increasing or sum of all objects, subjects, or participants that conform to a set of requirements. The present research was descriptive in nature. Cross-sectional study design was employed for the present research. The population of the present research was overall players belonging to two public sector universities of Pakistan (The Islamia University of Bahawalpur and Government College University Faisalabad) enrolled in various disciplines and have engaged diverse games.

The researchers used adapted and modified survey questionnaire with the permission of original authors (Ziółkowski, Strzałkowska, Sakłak, Zarańska, \&Bonisławska, 2012) as an instrument for data collection in the exiting research. The reliability was measured through Cronbach Alpha (.759) by pilot testing and validity was discussed with three referees in relevant subject. Sample may define as representative component of a target population which is worked upon by the researchers during their study. In the current research, total sample size was considered 250 respondents, whereas, responses were found 241.For this research, simple random sampling was used to select the samples. The actual data was 
collected randomly selected university players personally by the researchers. The SPSS (version-25) was employed for editing the data. Descriptive statistics, Pearson's correlation analysis and linear regression analysis were chosen to test the research hypotheses in the present research.

\section{Results and Discussions}

Descriptive statistics (frequency, mean, standard deviation and percentage) was utilized to measure the demographic information of respondents of the present research.

Table 1

Descriptive Statistics of Respondents about Age Level (n-241)

\begin{tabular}{ccccc}
\hline & Minimum & Maximum & Mean & Std. Deviation \\
\hline Age Level & 18 & 28 & 20.82 & 1.628 \\
\hline
\end{tabular}

Age level of 241 respondents was found between 18 to 28 years who were enrolled in various disciplines of both universities. Whereas, mean was measured 20.82 and std. deviation was measured 1.62 displayed in Table1.

The results of Pearson's correlation analysis were done to find out the relationship between sports involvement and ethical development of young university players.

Table 2

Correlation between Sports Involvement and Development of Young Players (n-241)

\begin{tabular}{|c|c|c|c|}
\hline & & $\begin{array}{c}\text { Sports } \\
\text { Involvement }\end{array}$ & $\begin{array}{l}\text { Ethical Development } \\
\text { of Young University } \\
\text { Players }\end{array}$ \\
\hline \multirow[t]{2}{*}{ Sports Involvement } & $\begin{array}{c}\text { Pearson } \\
\text { Correlation }\end{array}$ & -- & $.619^{* *}$ \\
\hline & Sig. (2-tailed) & & .000 \\
\hline \multirow{2}{*}{$\begin{array}{c}\text { Ethical Development of } \\
\text { Young University } \\
\text { Players }\end{array}$} & $\begin{array}{c}\text { Pearson } \\
\text { Correlation }\end{array}$ & $.619^{* *}$ & -- \\
\hline & Sig. (2-tailed) & .000 & \\
\hline \multicolumn{4}{|c|}{ **. Correlation is significant at the 0.01 level (2-tailed). } \\
\hline \multicolumn{4}{|c|}{$\begin{array}{l}\text { The results displayed in Table } 2 \text { showed that sports involvement was } \\
\text { significantly associated with ethical development of young players }(r=.619, p=.01) \text { at } \\
\text { universities. Correlation findings of both variables revealed that sports involvement } \\
\text { had positive and strong relationship with ethical development of young university } \\
\text { players. }\end{array}$} \\
\hline
\end{tabular}


Linear regression analysis was performed to examine the influence of sports involvement on ethical development of young university players.

Table 3

Descriptive Statistics Results (n-241)

\begin{tabular}{ccccc}
\hline & Minimum & Maximum & Mean & Std. Deviation \\
\hline $\begin{array}{c}\text { Development of Young } \\
\text { University Players }\end{array}$ & 11.00 & 35.00 & 19.6525 & 5.15888 \\
\hline Sports Involvement & 9.00 & 29.00 & 16.3972 & 4.37669 \\
\hline
\end{tabular}

Results of descriptive statistics in Table 3indicatedthemean and std. deviation scores of sports' involvement $(16.39,4.37)$ and ethical development of young university players $(19.65,5.15)$ accordingly.

Table 4

Model Summary Results

\begin{tabular}{cccccc}
\hline Model & $\mathrm{R}$ & R Square & $\begin{array}{c}\text { Adjusted R } \\
\text { Square }\end{array}$ & $\begin{array}{c}\text { Std. Error of } \\
\text { the Estimate }\end{array}$ & Durbin-Watson \\
\hline 1 & .610 & .460 & .454 & 4.45509 & 1.744 \\
\hline
\end{tabular}

The results shown the value of $\mathrm{R}$ was .610 (Adjust $\mathrm{R}$ square=.454), a value was found significant whereas, Std. Error of Estimate 4.45 and Durbin-Watson 1.74 as display in Table 4 . Sports involvement had a variance of $54.4 \%$ in outcome variable and significantly predicted to ethical development of young university players.

Table 5

ANOVA Results

\begin{tabular}{ccccccc}
\hline \multirow{2}{*}{ Model } & Sum of Squares & Df & $\begin{array}{c}\text { Mean } \\
\text { Square }\end{array}$ & F & Sig. \\
\hline \multirow{2}{*}{1} & Regression & 967.121 & 1 & 967.121 & 48.727 & .000 \\
\cline { 2 - 7 } & Residual & 2758.851 & 239 & 19.848 & & \\
\cline { 2 - 8 } & Total & 3725.972 & 240 & & & \\
\hline
\end{tabular}

The ANOVA results showed the value $F(1,239)=48.72$ and $p=.01$ that these values were found strongly and statistically significant as showed in Table 5.

Table 6

Coefficient Model Results

\begin{tabular}{ccccccc}
\hline & \multicolumn{2}{c}{$\begin{array}{c}\text { Unstandardized } \\
\text { Coefficients }\end{array}$} & $\begin{array}{c}\text { Standardized } \\
\text { Coefficients }\end{array}$ & t & \multirow{2}{*}{ Sig. } \\
\cline { 2 - 6 } & $\mathbf{B}$ & Std. Error & Beta & & \\
\hline \multirow{2}{*}{\begin{tabular}{c} 
(Constant) \\
\cline { 2 - 6 }
\end{tabular}} & 9.806 & 1.460 & & 6.718 & .000 \\
\hline $\begin{array}{c}\text { Sports } \\
\text { Involvement }\end{array}$ & .601 & .086 & .387 & 6.980 & .000 \\
\hline
\end{tabular}


The results of coefficients presented in Table 6 indicated that standardized of coefficients of sports involvement was $\beta=.387, t=6.98, p=.01$. The findings revealed that sports involvement significantly influenced ethical development of young university players. The total values of $\beta, t$ and $p$ were also found statistically significant.

The findings on the present study revealed that significant $(p=.01)$ relationship was investigated between sports involvement and ethical development of young university players. The sports involvement has positive association with ethical development of young players. Therefore, the results exposed strong relationship between sports involvement and ethical development of young players. The reason behind the significant relationship may be that as the involvement in sports increases as the young players will develop the moral and social values more among each other. A research conducted by Jones and Perkins (2006) concluded that sports involvement and development of players were significantly associated with each other. Another research conducted by Yusof (2013) investigated that significant relationship was found between involvement in sports and ethical development of players. Various prior researches were proved the results of the present research (Catalano et al., 2004; Yusof, Chuan, \& Shah,2013; Durlak et al., 2011; Gavin et al., 2010; Maslow \& Chung, 2013).

The results of the existing research exposed that model of linear regression analysis was established to find out the influence of sports involvement as a predictor factor on the development of young players (outcome variable). The findings revealed a significant influence of sports involvement on the development of young players. The reason may be behind the significant effect that the youth become sound due to involve in sports and get the advantages physically and physiologically. Vierimaa, Bruner, and Côté (2018) concluded that sports involvement had significant effect on development of players. The previous studies were confirmed the findings of the current research (Jones \& Perkins, 2006; Lubans et al., 2012; Maslow \& Chung, 2013; Yusof, 2013; Zeldin et al., 2013).

\section{Conclusion}

Involvement in sports plays a central character today in the development of young players and other individuals as well. It was concluded that involvement of young players in sports may become a source of development in their social, moral, and physical growth as well as ponder a positive and worthwhile sign for the healthy society. Sports association may likewise add to develop the social and selfawareness of youth. Young players may give advantages to socio-passionate improvement, personality work, character building, and good advancement including the declaration of qualities and sportsmanship practices as well as they may focus on their autonomy, collectivism, common good, dignity, and productivity characteristics. 


\section{Recommendations}

Keeping in view the findings and conclusion, the following recommendations were proposed. The results revealed significant effect of ethical development of university student players on sports involvement. Therefore, director sports, sports officers, and coaches in line with administration need to arrange and deliver lectures on ethical development of student players at universities. The director sports due to having more closely with university students need to promote such environment enrich with social and moral characteristics to diminish the crime rate in today society and enrich university student players by ethics as well. All dignities involved in sports need to intentionally develop a game setting and such atmosphere that encourage potential advantages to youth character advancement as opposed to undermining it so that they may expand their potentials at national and international level. 


\section{References}

Balsano, A.B., Phelps, E., Theokas, C., Lerner, J.V., \& Lerner, R.M. (2009). Patterns of early adolescents' participation in youth development programs having positive youth development goals. Journal of Research on Adolescence, 19(2), 249-259.

Coakley, J. (2011). Youth sports: What counts as "positive development?". Journal of Sport and Social Issues, 35(3), 306-324.

Tremblay, M.S., LeBlanc, A.G., Kho, M.E., Saunders, T.J., Larouche, R., Colley, R.C., \&Gorber, S.C. (2011). Systematic review of sedentary behaviour and health indicators in school-aged children and youth. International journal of behavioral nutrition and physical activity, 8(1), 98-112.

Durlak, J.A., Weissberg, R.P., Dymnicki, A., \&Schellinger, K.B. (2011). The impact of enhancing students' social and emotional learning: A meta-analysis of schoolbased universal interventions. Child Development, 82(1), 474-501.

Gavin, L.E., Catalano, R.F., David-Ferdon, C., Gloppen, K.M., \& Markham, C.M. (2010). A review of positive youth development programs that promote adolescent sexual and reproductive health. Journal of Adolescent Health, 46(3), S75S91.

Kegler, M., Young, K., Marshall, L., Bui, D., \&Rodine, S. (2005). Positive youth development linked with prevention in a Vietnamese-American community: Successes, challenges, and lessons learned. Journal of Adolescent Health, 37, 69-79.

Maslow, G.R., \& Chung, R.J. (2013). Systematic review of positive youth development programs for adolescents with chronic illness. Pediatrics, 131(5).

Catalano, R.F., Berglund, M.L., Ryan, J.A.M., Lonczack, H.S., \& Hawkins, J.D. (2004). Positive youth development in the United States: Research findings on evaluations of positive youth development programs. Annals of the American Academy of Political and Social Science, 591, 98-124.

Choi, Y., Harachi, T.W., Gillmore, M.R., \& Catalano, R.F. (2005). Applicability of the social development model to urban ethnic minority youth: Examining the relationship between external constraints, family socialization, and problem behaviors. Journal of Research on Adolescence, 15(4), 505-534.

Fredericks, J.A., \& Simpkins, S.D. (2012). Promoting positive youth development through organized after-school activities: Taking a closer look at participation of ethnic minority youth. Child Development Perspectives, 6(3), 280-287.

Jones, K.R., \& Perkins, D.F. (2006). Youth and adult perceptions of their relationships within community-based youth programs. Youth and Society, 38(1), 90-109. 
Lubans, D.R., Plotnikoff, R.C., \&Lubans, N.J. (2012). Review: A systematic review of the impact of physical activity programmes on social and emotional well-being in at-risk youth. Child and Adolescent Mental Health, 17(1), 2-13.

Vierimaa, M., Bruner, M.W., \&Côté, J. (2018). Positive youth development and observed athlete behavior in recreational sport. PLoS ONE, 13(1), e0191936.

Yusof, A. (2013). Sports Involvement and Academic Achievement: A Study of Malaysian University Athletes. International Education Studies, 6, 12-21.

Yusof, A., Chuan, C.,\& Shah, P. (2013). Academic Achievement and Sports Involvement of Malaysian University Athletes. Procedia - Social and Behavioral Sciences, 106, 273-281.

Zeldin, S., Christens, B.D., \& Powers, J.L. (2013). The psychology and practice of youth-adult partnership: Bridging generations for youth development and community change. American Journal of Community Psychology, 51, 385-397.

Ziółkowski, A., Strzałkowska, A., Sakłak, W., Zarańska, B., Bonisławska, L. (2012). Questionnaire of sports ethics - A tool for assessing moral behaviour in sport. Baltic Journal of Health and Physical Activity. 4(4), 277-283. 